\title{
Review
}

\section{A importância do sódio na alimentação de frangos de corte}

\author{
Andrey Sávio de Almeida Assunção ${ }^{1^{*}}$, Renata Aparecida Martins ${ }^{2}$, \\ Geyssane Farias de Oliveira ${ }^{1}$, Ádila Vasconcelos Marcon ${ }^{2}$
}

\begin{abstract}
RESUMO
Entre os minerais que demandam estudo na nutrição animal, o sódio se destaca pelas funções que exerce no organismo, como o transporte e a absorção de nutrientes pelas células, a transmissão de impulsos nervosos e o balanço eletrolítico. Ingredientes provenientes de fontes de origem animal possuem maiores níveis de sódio, entretanto as formulações de rações utilizadas na alimentação de frangos de corte são feitas com base no milho e no farelo de soja, tornando-se necessária a suplementação de sódio na alimentação das aves. No entanto a exigência de sódio em frangos de corte pode ser influenciada pelo sexo, pela fase de produção, pelas condições ambientais, pelo tipo de linhagem e pelas interrelações dos minerais. Dessa forma, é importante determinar os níveis ideais de sódio na alimentação e em cada fase de produção para que o crescimento dos frangos seja maximizado. Portanto, o objetivo com essa revisão de literatura foi expor a importância do sódio na alimentação de frangos de corte.
\end{abstract}

Palavras-chave: avicultura, balanço eletrolítico, minerais, sal comum

\section{Introdução}

Nos últimos anos, a avicultura de corte tem se destacado pela alta produtividade, em decorrência do melhoramento genético das linhagens

\footnotetext{
${ }^{1}$ Faculdade de Medicina Veterinária e Zootecnia, Universidade Estadual Paulista (Unesp), Botucatu, São Paulo, Brasil.

2 Faculdade de Ciências Agrárias, Universidade Federal da Grande Dourados, Dourados, MS, Brasil.

* Corresponding author: Faculdade de Medicina Veterinária e Zootecnia, Universidade Estadual Paulista (Unesp), Rua Professor Doutor Walter Mauricio Correa, s/n, Botucatu, São Paulo, Brasil, Cep: 18618-681. Telefone: (65) 99298-0680. E-mail: andreysavio@outlook.com
} 
aliado ao progresso nas áreas de manejo, sanidade, ambiência e nutrição, gerando, dessa forma, alimentos com proteína de alto valor biológico.

O Brasil é o segundo maior produtor de carne de frango do mundo, atrás dos Estados Unidos da América (EUA), seguido por China, União Europeia (EU) e Índia. Entretanto, nas exportações, ocupa o primeiro lugar, seguido pelo EUA, EU, Tailândia e China. Entre os principais importadores de carne de frango, no ano de 2016, destacaram-se o Japão, a Arábia Saudita, o México, a EU e o Iraque, respectivamente (Associação Brasileira de Proteína Animal - ABPA, 2017).

Nesse contexto, um dos principais fatores responsáveis pelas melhorias alcançadas para o desempenho produtivo na criação de frangos de corte são as pesquisas realizadas em nutrição. Assim, torna-se necessário balancear de forma exata os nutrientes da dieta (Barreto et al., 2007). Entre os nutrientes que demandam pesquisas, os minerais exercem funções importantes no metabolismo das aves (MACARI e MENDES, 2005; GOMES et al., 2013).

Minerais como o sódio $\left(\mathrm{Na}^{+}\right)$, o potássio $\left(\mathrm{K}^{+}\right)$e o cloro $(\mathrm{Cl})$ possuem função eletroquímica, pois atuam na manutenção do balanço ácido básico e no controle osmótico da distribuição da água no corpo (WATKINS et al., 2005; PETRUCCI, SCOTTA e JUNIOR, 2012; GOMES et al., 2013).

A importância do sódio na produção animal foi observada porque animais em estado de carência apresentavam um insaciável apetite pelo sal comum (BARROS et al., 2001; BARROS et al., 2004). Em dietas de aves, níveis elevados de sódio estimulam o consumo de água e favorecem o aumento da umidade das excretas, o que auxilia na produção de gases nocivos, como amônia e sulfídrico, além de dificultar o manejo e acarretar perdas econômicas (RAVINDRAN, COWIESON e SELLE, 2008; LIMA et al., 2015).

No grupo dos nutrientes minerais, o sódio destaca-se por vários motivos, entre eles, caracteriza-se por participar dos processos de 
transmissão de impulsos nervosos, na produção de sais biliares, na absorção de monossacarídeos, aminoácidos, pirimidinas e na ativação dos nervos da função muscular (GOFF, 2006; SILVA e PASCOAL, 2014). Por essa razão, é importante determinar os níveis ideais de sódio na alimentação dos frangos de corte em cada fase de produção para maximizar seu crescimento. No entanto, pelo fato de o sódio ser um nutriente de baixo custo e ter pouca influência no custo total da ração, é motivo de poucos estudos (RONDÓN et al., 2000). Pelo exposto, objetivou-se com essa revisão de literatura abordar a importância do sódio na alimentação de frangos de corte.

\section{Desenvolvimento}

\section{Classificação dos minerais}

Os minerais são elementos químicos de forma sólida, aspecto cristalino e que não se decompõem. A fração de minerais presente nos tecidos do organismo animal proporciona mudanças com o consumo de dietas desbalanceadas, seja pelo excesso ou pela falta desses minerais (DAGHIR, 2008; SILVA e PASCOAL, 2014). A carência ou o excesso de sódio na alimentação causa danos ao organismo animal e proporciona prejuízos ao desempenho zootécnico.

A classificação dos minerais está associada com as concentrações dos elementos nos tecidos, os quais definem as suas necessidades orgânicas. Por esta razão, classificam-se em macrominerais e microminerais ou elementos traços (Tabela 1) (BERTECHINI, 2012). Entretanto, cálcio (Ca), fósforo (P), sódio $(\mathrm{Na})$, enxofre $(\mathrm{S})$, potássio $(\mathrm{K})$, cloro $(\mathrm{Cl})$, e magnésio $(\mathrm{Mg})$, considerados macrominerais, tornam-se críticos para a nutrição das aves, pois participam em maiores quantidades nas dietas, ocupando um espaço que varia de $2 \%$ a $3 \%$ nas rações de frangos de corte (ARAUJO et al., 2008; BERTECHINI, 2014). 
Tabela 1 - Classificação dos minerais

\begin{tabular}{lll}
\hline Macrominerais & Microminerais & \\
\hline Cálcio (Ca) & Cobalto (Co) & Molibdênio (Mb) \\
Cloro (Cl) & Cobre (Cu) & Níquel (Ni) \\
Enxofre (S) & Cromo (Cr) & Selênio (Se) \\
Fósforo (P) & Ferro (Fe) & Silício (Si) \\
Magnésio (Mg) & Flúor (F) & Zinco (Zn) \\
Potássio (K) & Iodo (I) & \\
Sódio (Na) & Manganês (Mn) & \\
\hline Adaptado de Araujo et al. (2008) e Bertechini (2014). &
\end{tabular}

O sódio, de símbolo $\mathrm{Na}^{+}$, é o principal cátion monovalente encontrado no plasma sanguíneo (142 mmol/L) e nos fluídos extracelulares (140 $\mathrm{mmol} / \mathrm{L}$ ) do organismo animal (CUNNINGHAM e KLEIN, 2008). Pertence ao grupo dos metais alcalinos, de peso e número anatômico 23 e 11, respectivamente. Além disso, é relacionado com funções importantes, como o equilíbrio osmótico e a manutenção do $\mathrm{pH}$ corporal, a absorção de glicose, fósforo, cálcio, lisina e arginina (BORGES, 2001; MACARI e MENDES, 2005).

\section{Fontes de sódio na dieta das aves}

As fontes de minerais normalmente aplicadas para a formulação de rações na nutrição de poedeiras comerciais e frangos de corte são originárias de compostos inorgânicos que possuem origem geológica ou industrial. Esses compostos são empregados para a elaboração de rações em sua forma natural ou através de misturas minerais (premix), com o objetivo de incluir os minerais insuficientes na alimentação das aves (ARAUJO et al., 2008).

$\mathrm{Na}$ alimentação das aves, as principais fontes de sódio encontram-se, basicamente, na água de bebida, no sal comum $(\mathrm{NaCl})$ e nos grãos. Porém, o teor de sódio é baixo na maior parte dos ingredientes da ração, principalmente nas dietas à base de milho e farelo de soja, pois não atendem às exigências dietéticas desse mineral (SILVA, FLEMMING e BORGES, 2000). 
Nos ingredientes naturais, a concentração de sódio em comparação ao cloro e ao potássio é mais baixa (BORGES, 2006). As fontes de origem vegetal, como os grãos, apresentam baixas concentrações de sódio (Tabela 2) e maiores níveis de cloro. No entanto, fontes de origem animal, como farinha de carne e ossos, farinha de peixe e sangue, possuem maiores níveis de sódio (SUTTLE, 2010). Dessa forma, em razão de as rações serem formuladas à base de milho e farelo de soja, torna-se necessária a suplementação de sódio na alimentação das aves.

Existem inúmeras fontes de suplementação de sódio na alimentação de frangos de corte, destacando-se o cloreto de sódio $(\mathrm{NaCl})$, com 39,7 \% de $\mathrm{Na}$, e o Bicarbonato de sódio $\left(\mathrm{NaHCO}_{3}\right)$, com $27 \%$ de $\mathrm{Na}$, ambas de fonte inorgânica. Pesquisas têm demostrado que outras fontes, como carbonato de sódio $\left(\mathrm{Na}_{2} \mathrm{CO}_{3}\right)$, formiato de sódio $(\mathrm{HCOONa})$ e sulfato de sódio $\left(\mathrm{Na}_{2} \mathrm{SO}_{4}\right)$ podem ser utilizadas sem afetar o desempenho das aves (AHMAD et al., 2006; SILVA et al., 2009; MUSHTAQ, PARVIN e KIM, 2014).

A necessidade de incluir fontes adicionais nas rações é fundamental, principalmente quando a dieta não atende às exigências nutricionais de sódio, sendo essencial a suplementação desse mineral para o desenvolvimento das aves. Em razão disso, foram o motivo de estudo de Silva et al. (2009) ao avaliarem os efeitos das diferentes fontes de sódio nas rações (cloreto de sódio, bicarbonato de sódio e formiato de sódio com e sem adição de cloreto de amônia) sobre o desempenho produtivo e a umidade da cama em frangos de corte, fêmeas, de 22 a 42 dias de idade da linhagem Ross. Independente da fonte utilizada, não verificaram efeito no desempenho produtivo. Entretanto a umidade da cama foi maior nas aves que receberam o bicarbonato de sódio. Segundo os autores, o fornecimento de bicarbonato de sódio, possivelmente, originou uma sobrecarga no trato intestinal e, com isso, houve um aumento na quantidade de água, proporcionando maior umidade das excretas. 
Tabela 2 - Fontes e quantidades de sódio na dieta das aves.

\begin{tabular}{lc}
\hline Ingredientes & \% de Na $\mathbf{~}^{+}$na matéria natural \\
\hline Fonte vegetal & \\
\hline Milho (8,80\% de PB) & 0,01 \\
Milheto grão & 0,01 \\
Farelo de soja (45\% de PB) & 0,02 \\
\hline Fonte animal & 0,34 \\
\hline Farinha de penas e vísceras & 0,86 \\
Farinha de peixe (54 \% de PB) & 0,57 \\
Farinha de sangue & 0,66 \\
Farinha de carne e ossos (52 \% de PB) & \\
\hline Fontes inorgânicas & 39,70 \\
\hline Sal comum & 27,00 \\
Bicarbonato de sódio & 43,00 \\
Carbonato de Sódio & 32,40 \\
Sulfato de sódio &
\end{tabular}

Rostagno et al. (2017).

\section{Metabolismo do sódio}

O processo de absorção de minerais ocorre normalmente por transporte passivo, através da parede intestinal, em que as moléculas e íons se movimentam a favor de um gradiente de concentração, sendo permeado por controle hormonal e pela concentração de fluidos extracelulares. Enquanto isso, nos enterócitos intestinais, os minerais precisam estar em sua forma iônica, cátions e íons, para que ocorra de forma adequada o transporte e sua absorção (SILVA e PASCOAL, 2014).

O sódio é um mineral monovalente e extremamente solúvel, por esse motivo seu transporte é fácil, ao passo que sua absorção é realizada por meio de transporte ativo. Esse tipo de transporte exige gasto de energia, pois as células mobilizam moléculas e íons contra seus potenciais eletroquímicos. Além disso, é considerado um mineral absorvido rapidamente pelo intestino delgado, embora a sua absorção possa acontecer em todo o intestino (CUNNINGHAM e KLEIN, 2008; SILVA e PASCOAL, 2014; MASSUQUETO, MAIORKA e MACARI, 2017).

Segundo Nelson e Cox (2014), existem dois tipos de transporte ativos, o primário e o secundário. No primário, a quebra de adenosina trifosfato (ATP) em adenosina difosfato (ADP + Pi) libera energia com o objetivo de 
movimentar o soluto contra um gradiente eletroquímico. Por outro lado, no transporte ativo secundário, o deslocamento do sódio a favor de seu gradiente eletroquímico disponibiliza energia necessária para direcionar o cotransporte de um segundo soluto contra o seu potencial eletroquímico.

Conforme Cunningham e Klein (2008), no trato intestinal, particularmente no intestino delgado, a absorção de sódio pode ocorrer por três mecanismos distintos. O primeiro mecanismo de absorção, caracterizado como transporte ativo secundário, é o principal meio de absorção de sódio. Esse mecanismo é realizado através das proteínas de cotransporte de sódio em conjunto com moléculas orgânicas, tais como a glicose e os aminoácidos.

O segundo mecanismo é a absorção acoplada de sódio ao íon cloreto, ambos trabalhando juntos para facilitar o transporte deles na membrana apical, em que se forma o ácido carbônico $\left(\mathrm{H}_{2} \mathrm{CO}_{3}\right)$ no interior do enterócito, através da água $\left(\mathrm{H}_{2} \mathrm{O}\right)$ e do dióxido de carbono $\left(\mathrm{CO}_{2}\right)$. $\mathrm{O}$ íon hidrogênio é trocado pelo sódio luminal através da membrana apical. Durante essa troca, haverá a formação do bicarbonato $\left(\mathrm{HCO}_{3}{ }^{-}\right)$, pela ação da enzima anidrase carbônica. Na troca de íon hidrogênio $\left(\mathrm{H}^{+}\right)$pelo íon sódio $\left(\mathrm{Na}^{+}\right)$, aumentamse as concentrações de bicarbonato dentro da célula, ao mesmo tempo em que o gradiente de bicarbonato conduz a ação da troca de $\mathrm{Cl} / \mathrm{HCO}_{3}$, resultando na troca de bicarbonato intracelular pelo íon cloro luminal (CUNNINGHAM e KLEIN, 2008).

O terceiro e último mecanismo de absorção é realizado por difusão simples, classificado como transporte passivo. O gradiente eletroquímico pode existir para o sódio na membrana apical do enterócito. Provavelmente, o movimento de sódio direto não acoplado pode acontecer por intermédio da membrana, se os canais de íons estiverem abertos. No entanto, a probabilidade de absorção de sódio com esse mecanismo é pequena, em vista disto, sua importância no organismo animal é relativamente limitada (CUNNINGHAM e KLEIN, 2008). 


\section{Funções do sódio no transporte de nutrientes}

A bomba de sódio-potássio $\left(\mathrm{Na}^{+}-\mathrm{K}^{+}\right)$é o meio de transporte ativo mais estudado em virtude de suas características, uma vez que funciona como um mecanismo de transporte que bombeia ao mesmo tempo íons de sódio para fora da célula e íons de potássio para dentro dela, através da membrana celular. Dessa forma, a bomba é responsável pela manutenção das diferenças de concentração entre o sódio e o potássio, isto é, realiza papel essencial no controle do volume celular, porque sem sua função a maior parte das células iria inchar e estourar (GUYTON e HALL, 2011).

De acordo com Guyton e Hall (2011), a bomba de sódio-potássio transporta dois íons de potássio para o interior da célula e simultaneamente conduz três íons de sódio para fora dela. Porém, a energia básica para esse processo é proveniente da quebra de uma molécula de adenosina-trifosfato (ATP), dividindo-a em difosfato de adenosina (ADP) e liberando uma ligação fosfato de alta energia (Pi). Essa energia promove alteração química e conformacional da molécula da proteína transportadora, possibilitando dessa forma o movimento de três íons de sódio para fora e de dois íons de potássio para dentro da célula.

Gal-Garber et al. (2003) pesquisaram 0,05 \%; 0,14 \% e 0,32 \% de sódio na ração de pintainhos da linhagem Ross, e analisaram um provável aumento da atividade da bomba de sódio-potássio no intestino delgado na presença de altos níveis de sódio. Os mesmos autores verificaram que a ingestão excessiva de sódio pode influenciar negativamente $\mathrm{o}$ comportamento cinético do intestino delgado das aves, supostamente reduzindo a absorção, uma vez que a afinidade $\left(\mathrm{K}_{\mathrm{m}} \mathrm{mmol} / \mathrm{L}\right)$ da bomba de sódio-potássio é reduzida com o excesso de sódio no organismo.

Mencionado como o principal mecanismo pelo qual o sódio é transportado (proteínas de cotransporte de sódio) no intestino delgado, especialmente no jejuno, a absorção desse mineral é mais alta em virtude da 
presença de algumas substâncias, tais como aminoácidos, glicose e galactose, que estão neutros no lúmen da célula, os quais atravessam a membrana utilizando as proteínas carreadoras. Nesse contexto, a função do sódio no transporte de nutrientes é pertinente, uma vez que a absorção do sódio está atrelada com outras substâncias, como os carboidratos, os aminoácidos e as vitaminas (GOFF, 2006; MASSUQUETO, MAIORKA e MACARI, 2017).

\section{Exigência nutricional de sódio para frangos de corte}

A exigência de sódio em frangos de corte pode ser determinada em função de alguns fatores que a influenciam, tais como o sexo, a espécie, a fase de produção, as fontes e as quantidades dos minerais presentes na dieta, as condições ambientais, as necessidades orgânicas, a taxa de crescimento, o tipo de linhagem e as inter-relações dos minerais (COSTA et al., 2012; BERTECHINI, 2014).

A recomendação de sódio difere na literatura científica, não havendo um consenso entre pesquisadores, conselhos nacionais de pesquisas e tabelas de exigências nutricionais para aves. O National Research Council (1994) preconiza para frangos de corte, machos e fêmeas, 0,20\%; 0,15\% e 0,12 \% de sódio na ração nas seguintes fases: 0 a 3 semanas, 3 a 6 semanas e 6 a 8 semanas de idade, respectivamente. Essas exigências são inferiores às recomendações feitas por Rostagno et al. (2017), de 0,227 \% (1-7 dias), 0,221 \% (8-21 dias), 0,211\% (22-33 dias), 0,201\% (34-42 dias) e de 0,195\% (43-46 dias) de sódio para machos com desempenho médio-superior e semelhantes ao recomendado por Bertechini (2014), 0,21\% (1-21 dias) e 0,18\% de $\mathrm{Na}(22$ dia até o abate).

Borges et al. (1998), ao adicionarem 0,30\%; 0,45\%; 0,60\%; 0,75\% e $0,90 \%$ de sal $(\mathrm{NaCl})$ na dieta de frangos de corte (machos e fêmeas), não observaram efeito no desempenho produtivo na fase de 1 a 21 dias de idade, sugerindo nessa fase $0,30 \%$ de $\mathrm{NaCl}$ na ração. No entanto, na fase de 22 a 
42 dias, machos apresentaram maiores ganho de peso, mortalidade e consumo de ração e água do que as fêmeas. Esses resultados podem ser explicados pela maior taxa de crescimento dos machos em relação às fêmeas.

Com o objetivo de determinar a exigência de sódio para frangos de corte na fase inicial (1 a 21 dias), Barros et al. (2001), com base nas respostas de desempenho, recomendaram 0,256 \% e 0,255 \% de sódio para machos e fêmeas, respectivamente. Entretanto, independente do sexo, com níveis elevados de sódio, o desempenho das aves foi influenciado de forma negativa. Essa piora do desempenho estaria supostamente relacionada com o maior gasto energético da bomba de $\mathrm{Na}-\mathrm{K}$, na tentativa de controlar o gradiente eletroquímico entre o meio extra e intracelular ou em razão do excesso de sódio.

Na fase pré-inicial (1 a 7 dias de idade) de frangos de corte, Rondón et al. (2000) determinaram 0,28 \% de sódio na ração. Esse valor foi superior ao recomendado por Silva et al. (2006), ao avaliarem níveis crescentes de sódio $(0,15 \% ; 0,19 \% ; 0,23 \% ; 0,27 \% ; 0,31 \%$ e $0,35 \%)$ na ração sobre o desempenho de pintinhos (1 a 21 dias), em que estimaram 0,19 \% de sódio para um bom ganho de peso, melhor conversão alimentar e consumo de ração.

Ao avaliarem $0,12 \% ; 0,24 \% ; 0,36 \%$ e $0,48 \%$ de $\mathrm{Na}$ e dois balanços eletrolíticos (160 e $240 \mathrm{mEq} / \mathrm{kg}$ ) na dieta de frangos de corte machos da linhagem Ross 308, Viera et al. (2003) verificaram que na primeira semana de vida, com o aumento de sódio, o consumo de água aumentou e o peso corporal e a conversão alimentar melhorou. Entretanto a mortalidade foi maior à medida que o nível de sódio aumentou, porém, isso foi reduzido quando utilizou $240 \mathrm{mEq} / \mathrm{kg}$ na dieta. No mesmo estudo, até os quatro primeiros dias de idade, o aumento de $160 \mathrm{mEq} / \mathrm{kg}$ para $240 \mathrm{mEq} / \mathrm{kg}$ demonstrou benefícios sobre o ganho de peso e a conversão alimentar.

Níveis inferiores de sódio na alimentação de frangos de corte pode comprometer o desempenho zootécnico. Dessa forma, aves carentes de sal 
comum $(\mathrm{NaCl})$, na tentativa de controlar a homeostasia corporal, aumentam sua taxa metabólica basal, afetando de forma negativa o desempenho. Do mesmo modo, níveis superiores de sódio têm efeito negativo sobre o desempenho. Esse fato pode ser desencadeado pela toxidez ou pelo aumento do gasto de energia pela bomba de $\mathrm{Na}-\mathrm{K}$ para o controle da homeostase corporal, ou ainda pelo aumento da umidade da cama, tornando-a mais propícia ao crescimento de agentes causadores de doenças (BARROS et al., 2004).

A exigência de sódio muda também para aves do tipo caipira, tanto para a produção de ovos quanto de carne. Pinheiro et al. (2011), com o objetivo de determinar os níveis de inclusão de cloreto de sódio $(\mathrm{NaCl})$ em rações para aves, machos e fêmeas, da linhagem colonial nas fases inicial (1 a 28 dias), crescimento ( 28 a 56 dias) e final (56 a 84 dias) criadas em semiconfinamento, sugeriram $0,53 \%$ de $\mathrm{NaCl}$ (fase inicial) para ambos os sexos, de $0,40 \%$ e de $0,43 \%$ (crescimento) para machos e fêmeas, respectivamente, e de $0,25 \%$ de $\mathrm{NaCl}$ (fase final) para ambos os sexos. Nesse experimento, verificaram aumento do consumo de água pelas aves à medida que se elevou o nível de sal na ração. Conforme Borges et al. (1998), a temperatura da água ou do ambiente de criação pode afetar a ingestão de água, tornando difícil o valor correto que o aumento do nível de sal causa na ingestão.

Ao pesquisarem o efeito de três vias de fornecimento de $\mathrm{NaCl}$ (100 \% na ração, 50 \% na ração/50\% na água e 100 \% na água), durante a fase inicial (1-21 dias de idade) de frangos de corte machos da linhagem Ross 308, Villanueva et al. (2015) não observaram efeito na ingestão de água nos primeiros sete dias de vida. Segundo os autores, a atuação do sódio no consumo de água se deve, provavelmente, à quantidade de sódio e não à via de fornecimento.

Watkins et al. (2005), ao pesquisarem os efeitos dos níveis de sódio e cloro na água de bebida de frangos de corte de 1 a 21 dias de idade, 
deduziram que o sódio pode ser adicionado parcial ou totalmente através da água. Esses autores propõem que o sódio suplementado na água de bebida é mais eficaz, em razão de o mineral ser consumido separadamente dos demais ingredientes da ração, sujeito de ser absorvido de forma rápida.

Estudando o efeito de dois níveis de cloreto de sódio (2 e $6 \mathrm{~g} / \mathrm{Kg}$ de alimento) em frangos de corte, machos da linhagem Cobb 500, de 21 a 42 dias de idade, submetidos ao estresse térmico $\left(30\right.$ a $32{ }^{\circ} \mathrm{C}$ a cada cinco horas/dia), Neto, Ceccantini e Fernandes (2013) notaram melhor desempenho e rendimento de carcaça quando foi adicionado $6 \mathrm{~g}$ de $\mathrm{NaCl} / \mathrm{Kg}$ de alimento na dieta.

\section{Homeostase ácido-básico}

Para manter-se viva, a célula carece de nutrientes. Para esse fim, deve haver trocas entre os líquidos intra e extracelulares por intermédio dos mecanismos de transporte celular como a osmose, a difusão e o transporte passivo e ativo. A manutenção do ambiente interno em condições adequadas denomina-se homeostasia ou homeostase (CAVALCANTE, LOIOLA, e JUNIOR, 2011).

Segundo Borges (2001), a osmorregulação celular só é alcançada por meio da homeostasia entre os minerais do fluído intracelular (íons de potássio, magnésio e fosfato) e extracelular (sódio, cloro, cloreto e íons bicarbonato). Em condições adequadas, o volume de água e de eletrólitos é mantido parcialmente constante. No entanto, no momento em que se verifica a perda de $\mathrm{Na}^{+}$ou de $\mathrm{K}^{+}$a osmolalidade dos fluidos intra e extracelulares diminui. De acordo com Macari (2017), o primeiro reflexo das aves ao excesso de sódio no plasma é a sede. Esse fato aumenta a ingestão de água e decresce proporcionalmente à concentração de sódio

$\mathrm{Na}$ homeostase mineral, os elementos minerais podem ser divididos em dois componentes no que se refere às rotas de excreção endógenas. A primeira rota está relacionada com as perdas nas fezes, que são controladas 
pelo sistema digestivo e pelas glândulas anexas, tais como o fígado e o pâncreas. A segunda rota é dependente dos rins pela excreção renal, controlada pela reabsorção nos túbulos renais (SILVA e PASCOAL, 2014).

Conforme Guyton e Hall (2011), a homeostase de sódio no organismo animal está envolvida com a síntese de hormônios e enzimas, como a aldosterona e a renina. Esses elementos estão associados com o estímulo da excreção ou retenção nos túbulos renais e com a regulação dos rins quando ocorrem as perdas de eletrólitos e água no organismo.

A aldosterona, produzida pelas glândulas adrenais, é a responsável por estimular a reabsorção de sódio nos túbulos renais. Quando a concentração plasmática de sódio for baixa, o rim libera uma enzima denominada renina, a qual converte o angiotensinogênio, circulante no sangue, em angiotensina I. Em seguida, nos pulmões, é convertido em angiotensia II. A angiotensina II estimula a produção e a secreção de aldosterona pelas glândulas adrenais, aumentando dessa forma a eliminação de potássio $\left(\mathrm{K}^{+}\right)$e a reabsorção de sódio $\left(\mathrm{Na}^{+}\right)$pelos rins $(\mathrm{GOFF}$, 2006; MASSUQUETO, MAIORKA e MACARI, 2017).

Nos frangos de corte, a homeostase ácido-básica pode ser influenciada pelo meio ambiente em que vivem, pelo metabolismo e pela alimentação que consomem (OLANREWAJU et al., 2007). Macrominerais como o sódio, o potássio e o cloro são fundamentais para a manutenção do equilíbrio ácidobase. $\mathrm{Na}$ dieta, tais elementos são exigidos em quantidades mínimas e, para satisfazer suas necessidades nutricionais, é de suma importância que a proporção entre eles seja ideal para conservar a homeostase ácido-básica e alcançar o máximo desempenho (BORGES, 2006).

\section{Balanço Eletrolítico (BE)}

Eletrólito é definido como uma substância química que, dissociada ou ionizada em seus constituintes iônicos, forma cátions e ânions. Em vista disso, transforma-se em um condutor de eletricidade e proporciona a 
manutenção do equilíbrio ácido-base corporal. Todavia, no organismo animal, o balanço dos eletrólitos pode afetar o desempenho produtivo, o transporte e a absorção de determinados nutrientes, como aminoácidos e minerais, o desenvolvimento ósseo, a qualidade da cama e influenciar nas respostas ao estresse calórico (BORGES, MAIORKA e SILVA, 2003; OLIVEIRA, ARANTES e STRINGHINI, 2010; GAMBA et al., 2015).

O balanço eletrolítico (BE) refere-se ao equilíbrio iônico dos fluidos orgânicos, permitindo a regulação do balanço ácido-básico para a manutenção da homeostase orgânica, em que os cátions sódio e potássio e o ânion cloro são elementos fundamentais para esse equilíbrio (BERTECHINI, 2012). Assim, na dieta das aves, o BE é determinado pela diferença entre esses elementos (cátions e ânions).

Mongin, em suas pesquisas a respeito do BE em aves e suínos, afirma que o equilíbrio adequado de sódio, potássio e cloro é fundamental para o desempenho produtivo, uma vez que o desequilíbrio eletrolítico pode causar problemas como acidose ou alcalose e tornar ineficientes as vias metabólicas do organismo animal. Para o autor, o BE é definido pelo resultado da soma dos íons $\mathrm{Na}^{+}$e $\mathrm{K}^{+}$, menos o $\mathrm{Cl}$ - (MONGIN, 1980).

De acordo com Mongin (1981), para manter o BE, o animal deve regular a ingestão e a excreção de ácidos e bases. Segundo o autor, quando o animal não está com excesso nem com deficiência de ácido ou base, ou seja, em $\mathrm{BE}$ adequado, é representado pela seguinte fórmula:

$$
\text { (Cátions - Ânions })_{\text {ingeridos }}=(\text { Cátions }- \text { Ânions })_{\text {excretados }}
$$

O valor recomendado de BE por Mongin (1981) é expresso em $\mathrm{mEq} / \mathrm{kg}$ (cátions e ânions/kg), e para frangos de corte, é de $250 \mathrm{mEq} / \mathrm{kg}$, porém esse valor difere na literatura científica e pode ser calculado pela seguinte equação: Número de Mongin $(\mathrm{NM})=\% \mathrm{Na}^{+} \mathrm{x} 10000 / 22,990 *+\% \mathrm{~K}^{+} \mathrm{x}$ 10000/39,102* - + \%Cl- x 10000/35,453* (*Equivalente grama de $\mathrm{Na}^{+}, \mathrm{K}^{+} \mathrm{e}$ $\mathrm{Cl}-$, respectivamente). 
Adedokun e Applegate (2014), ao avaliarem dois níveis de BE (108 e $219 \mathrm{mEq} / \mathrm{kg}$ de dieta) e duas proporções de amido-dextrose de milho nas perdas de aminoácidos endógenos ileais nas dietas de frangos de corte (Ross 708) aos 48 dias de idade, não observaram perda de peso corporal entre os níveis de BE. No entanto, o consumo de ração foi menor quando as aves foram alimentadas com BE de $219 \mathrm{mEq} / \mathrm{kg}$. Esse motivo pode estar relacionado com os altos níveis de $\mathrm{Na}^{+}, \mathrm{K}^{+}$e $\mathrm{Cl}^{-}$. $\mathrm{Na}$ mesma pesquisa, com altos valores de BE (219 mEq/kg), houve aumento na quantidade de secreção de aminoácidos de origem endógenas e das perdas de aminoácidos ileais nos frangos. Os autores explicam que esse fato teve influência das secreções digestivas, das células epiteliais esmagadas e das mucosas intestinais diferentes.

Ao testarem 150, 225, 300 e $375 \mathrm{mEq} / \mathrm{kg}$ de BE em dietas de frangos de corte na fase inicial de 1 a 21 dias de idade, Ravindran, Cowieson e Selle (2008) não notaram efeito no consumo de ração entre os níveis de $\mathrm{BE}$ e houve redução no ganho de peso ao nível de $375 \mathrm{mEq} / \mathrm{kg}$. Entretanto, com níveis de 300 e $375 \mathrm{mEq} / \mathrm{kg}$, a digestibilidade aparente de aminoácidos ileal reduziu e aumentou a umidade das excretas. De acordo com os autores, provavelmente foi em decorrência do aumento dos níveis de sódio, pois uma das respostas fisiológicas do corpo ao excesso de sódio é, além do aumento do consumo de água, a excreção do excesso de sódio via urina e a redução da taxa de filtração glomerular renal.

Em seus estudos, Olanrewaju et al. (2007), quando analisaram BE moderado (174 mEq/kg) e BE alto $(241 \mathrm{mEq} / \mathrm{kg})$ em dietas de frangos de corte nas fases inicial, crescimento e final, o BE alto de $241 \mathrm{mEq} / \mathrm{kg}$ foi suficiente para aliviar parcialmente o estresse adaptativo induzido pelo hormônio adrenocorticotrópico. Apesar disso, os autores concluíram que o BE nas dietas não desempenhou um papel importante no alívio do estresse induzido pelo hormônio. No entanto, Gamba et al. (2015), quando utilizaram $350 \mathrm{mEq} / \mathrm{kg}$ nas rações de frangos de corte submetidos ao estresse térmico, 
verificaram que o desempenho zootécnico melhorou e o estresse calórico foi minimizado.

Ao analisarem os efeitos de diferentes níveis de $\mathrm{Na}(0,10 ; 0,22 ; 0,34$ e 0,46\%) e diferentes $\mathrm{BE}(100,150,200,250$ e $300 \mathrm{mEq} / \mathrm{kg})$ em dietas préiniciais de frangos de corte, Maiorka et al. (2004) observaram efeito positivo no ganho de peso, na conversão alimentar e no consumo de água e ração. Nesse estudo, até a primeira semana de vida (1-7 dias), tanto o nível de sódio quanto o BE não influenciaram na umidade das excretas.

Oliveira, Arantes e Stringhini (2010), ao analisarem o efeito do balanço eletrolítico (200, 240, 280 e $320 \mathrm{mEq} / \mathrm{kg}$ ) da ração sobre os parâmetros ósseos (densidade óssea, morfometria e índice de peso/comprimento do fêmur) e da cama (umidade \%, pH, amônia volatilizada e densidade) de frangos de corte de 22 a 38 dias de idade, não observaram influência dos diferentes BE sobre as características ósseas. Aos 21 e 38 dias de idade não houve diferença no $\mathrm{pH}$ e na amônia volatizada, entretanto observaram efeito linear crescente na umidade da cama quando o $\mathrm{BE}$ ultrapassou $280 \mathrm{mEq} / \mathrm{kg}$.

\section{Considerações finais}

A importância do sódio na alimentação dos frangos de corte é bastante notável, principalmente pela conservação das funções relacionadas aos processos vitais no organismo animal. Esse mineral, na alimentação, é exigido em quantidades mínimas para atender às necessidades nutricionais das aves e a relação na formulação das rações é indispensável para que o desempenho zootécnico seja maximizado. 


\title{
The importance of sodium in the feeding of broilers
}

\begin{abstract}
Among the minerals that require study in animal nutrition, sodium is notable for its functions in the body, such as transport and absorption of nutrients by cells, transmission of nerve impulses and electrolyte balance. Ingredients from sources of animal origin have higher levels of sodium; however, rations formulations used to feeding broilers are based on corn and soybean meal, making it necessary to supplement sodium in poultry feeding. However, the requirement of sodium in broilers can be influenced by sex, production stage, environmental conditions, lineage type and interrelations of minerals. In this way, it is important to determine the optimal levels of sodium in the feeding and at each stage of production so that its growth is maximized. Therefore, the objective with this literature review was to expose the importance of sodium in the feeding of broilers.

Keywords: poultry, electrolytic balance, minerals, salt.
\end{abstract}

\section{Referências}

ADEDOKUN, S.A.; APPLEGATE, T.J. Dietary electrolyte balance influences ileal endogenous amino acid losses in broiler chickens. Poultry Science, Oxford, v. 93, p. 935-942, 2014.

AHMAD, T.; MUSHTAQ, T.; MAHR-UN-NISA.; SARWAR, M.; HOOGE, D.M.; MIRZA, M.A. Effect of different non-chloride sodium sources on the performance of heat-stressed broiler chickens. British Poultry Science, Cambridge, v. 47, n. 3, p. 249-256, 2006.

ARAUJO, J.A.; SILVA, J.H.V.; AMÂNCIO, A.L.L.; LIMA, C.B.; OLIVEIRA, E.R.A. Fontes de minerais para poedeiras. Acta Veterinária Brasilica, Mossoró, v. 2, p. 53-60, 2008.

ASSOCIAÇÃO BRASILEIRA DE PROTEÍNA ANIMAL. Relatório anual de 2017. Disponível em: http://abpa-br.com.br/setores/avicultura/publicacoes/relatoriosanuais/2017>. Acesso em: $01 \mathrm{dez} .2017$. 
BARRETO, S.L.T.; ARAUJO, M.S.; UMIGI, R.T.; MOURA, W.C.O.; COSTA, C.H.R.; SOUSA, M.F. Níveis de sódio em dietas para codorna japonesa em pico de postura. Revista Brasileira de Zootecnia, Viçosa, v. 36, p. 1559-1565, 2007.

BARROS, J.M.S.; GOMES, P.C.; ROSTAGNO, H.S.; ALBINO, L.F.T.; NASCIMENTO, A.H. Exigência nutricional de sódio para frangos de corte de 1 a 21 dias de idade. Revista Brasileira de Zootecnia, Viçosa, v. 30, n. 3, p. 1044-1051, 2001.

BARROS, J.M.S.; GOMES, P.C.; ALBINO, L.F.T.; ROSTAGNO, H.S.; COSTA, L.F. Exigência de sódio para frangos de corte nas fases de crescimento (22 a 42 dias) e final (43 a 53 dias). Revista Brasileira de Zootecnia, Viçosa, v. 33, p. 1721-1733, 2004.

BERTECHINI, A.G. Nutrição de monográstricos. 2.ed. Lavras: Editora UFLA, 2012. 373p.

BERTECHINI, A.G. Exigências de minerais para aves. In: SAKAMOURA, N.K.; SILVA, J.H.V.; COSTA, F.G.P.; FERNANDES, J.B.K.; HAUSCHILD, L. Nutrição de não ruminantes. Jaboticabal: Funep-Unesp, 2014. p. 375-388.

BORGES, S.A.; ARIKI, J.; JERÔNIMO, J.R.R.; MARTINS, C.L.; MORAES, V.M.B. Níveis de cloreto de sódio em rações para frangos de corte. Arquivo Brasileiro de Medicina Veterinária e Zootecnia, Belo Horizonte, v. 50, p. 619-624, 1998.

BORGES, S.P. Balanço eletrolítico $\left(\mathrm{Na}^{+}+\mathrm{K}^{+}-\mathrm{Cl}\right)$ e sua interrelação com o equilíbrio ácido-base em frangos de corte submetidos a estresse calórico. 2001. 101 f. Tese (Doutorado em Zootecnia) - Universidade Estadual Paulista, Jaboticabal, SP, 2001.

BORGES, S.A.; MAIORKA, A.; SILVA, A.V.F. Fisiologia do estresse calórico e a utilização de eletrólitos em frangos de corte. Ciência Rural, Santa Maria, v. 33, p. 975-981, 2003. 
BORGES, S.A. Aplicação do conceito de balanço eletrolítico para aves. In: CONFERÊNCIA APINCO 2006 DE CIÊNCIA E TECNOLOGIA AVÍCOLAS, 2006, Santos, São Paulo, 2006, p. 123-137.

CAVALCANTE, J.S.; LOIOLA, M.I.B.; JUNIOR, E.S.N. Coordenação da vida. 2.ed. Natal: EDUFRN, 2011. 220p.

COSTA， F.G.P.; FIGUEIREDO-LIMA， D.F.; LIMA， M.R.; PINHEIRO， S.G.; GOULART, C.C.; SILVA, J.H.V.; BARALDI-ARTONI, S.M.; BARREIRO, F.R.; GIVISIEZ, P.E.N. Sodium levels for japonese quail at initial phases. Poultry Science, Oxford, v. 91, p. 1128-1134, 2012.

CUNNINGHAM, J.G.; KLEIN, B.G. Tratado de fisiologia veterinária. 4.ed. Rio de Janeiro: Elsevier, 2008. 710p.

DAGHIR, N.J. Poultry production in hot climates. 2.ed. Cambridge: CAB international, 2008. 401p.

GAL-GARBER, O.; MABJEESH, S.J.; SKLAN, D.; UNI, Z. Nutrient transport in the small intestine: $\mathrm{Na}^{+}, \mathrm{K}^{+}$-ATPase expression and activity in the small intestine of the chicken as influenced by dietary sodium. Poultry Science, Oxford, v. 82, p. 1127-1133, 2003.

GAMBA, J.P.; RODRIGUES, M.M.; GARCIA, N.M.; PERRI SHV, FARIA JÚNIOR MJ DE A, PINTO MF. The strategic application of electrolyte balance to minimize heat stress in broilers. Revista Brasileira de Ciência Avícola, Campinas, v. 17, p. 237-246, 2015.

GOFF, J.P. Minerais. In: REECE, W.O. DUKES, fisiologia dos animais domésticos. 12.ed. Rio de Janeiro: Guanabara Koogan; 2006. p. 532-555. GOMES, P.C.; REIS, R.S.; BARRETO, S.L.T.; ALMEIDA, R.L. Tópicos em manejo de matrizes pesadas. Viçosa, MG: Ed. UFV; 2013. 122p. 
GUYTON, A.C.; HALL, J.E. Tratado de fisiologia médica. 12.ed. Rio de Janeiro: Elsevier; 2011. 1173p.

LIMA, H.J.D.; BARRETO, S.L.T.; PAULA, E.; DUTRA, D.R.; COSTA, S.L.; ABJAUDE, W.S. Niveis de sódio na ração de codorna japonesas em postura. Revista Brasileira de Saúde e Produção Animal, Bahia, v. 16, p. 73-81, 2015.

MACARI, M. Ingestão de água: mecanismos regulatórios. In: MACARI, M.; MAIORKA, A. Fisiologia das aves comerciais. Jaboticabal: Funep, 2017. cap. 16, p. 406-417.

MACARI, M.; MENDES, A.A. Manejo de matrizes de corte. Campinas: FACTA, 2005. 421p.

MAIORKA, A.; MAGRO, N.; BARTELS, H.A.S.; KESSELER, A.M.; PENS JR, A.M. Different sodium levels and electrolyte balances in pre-starter diets for broilers. Revista Brasileira de Ciência Avícola, Campinas, v. 6, n. 3, p. 143-146, 2004.

MASSUQUETO, A.; MAIORKA, A.; MACARI, M. Absorção de minerais. In: MACARI, M.; MAIORKA, A. Fisiologia das aves comerciais. Jaboticabal: Funep, 2017. cap. 13, p. 322-328.

MONGIN, P. Electrolytes in nutrition: a review of basic principles and practical application in poultry and swine. In: IMC NUTRITION CONFERENCE, 1980, Melbourne, Orlando: IMC, 1980. p. 1-15.

MONGIN, P. Recent advances in dietary anion-cation balance: application in poultry. Proceedings of the Nutrition Society, Cambridge, v. 40, p. 285-294, 1981.

MUSHTAQ, M.M.H.; PARVIN, R.; KIM, J. Carcass and body organ characteristics of broilers supplemented with dietary sodium and sodium salts under a phase 
feeding system. Journal of Animal Science and Technology, Londres, v. 56, n. 4, p. 1-7, 2014.

National Research Council. Nutrient requeriments of poultry. 9.ed. Washigton: National Academy Press, 1994. 176p.

NELSON, D.L.; COX, M.M. Princípios de bioquímica de lehninger. 6.ed. Porto Alegre: Artmed, 2014. 1259p.

NETO, R.M.; CECCANTINI, M.L.; FERNANDES, J.I.M. Effects of methionine source, arginine:lysine ratio and sodium chloride level in the diets of grower broilers reared under high-temperature conditions. Revista Brasileira de Ciência Avícola, Campinas, v. 15, p. 151-160, 2013.

OLANREWAJU, H.A.; THAXTON, J.P.; DOZIER, 3rd. W.A.; BRANTON, SL. Electrolyte diets, stress, and acid-base balance in broiler chickens. Poultry Science, Oxford, v. 86, p. 1363-1371, 2007.

OLIVEIRA, M.C.; ARANTES, U.M.; STRINGHINI, J.H. Efeito do balanço eletrolítico da ração sobre parâmetros ósseos e da cama de frango. Biotemas, Florianópolis, v. 23, n. 1, p. 203-209, 2010.

PETRUCCI, F.B.; SCOTTA, B.A.; JUNIOR, J.G.V. Minerais para poedeiras comerciais. In: DEMINICIS, B.B.; MARTINS, C.B.; SIQUEIRA, J.B. Tópicos especiais em ciência animal I. Alegre, ES: Ed. CAUFES, 2012. Cap. 7, p. 59-68.

PINHEIRO, S.R.F.; SAKOMURA, N.K.; KAWAUCHI, I.M.; BONATO, M.A.; DORIGAM, J.C.P.; FERNANDES, J.B.K. Níveis de cloreto de sódio para aves de corte da linhagem colonial criadas em semiconfinamento. Revista Brasileira de Zootecnia, Viçosa, v. 40, p. 1545-1553, 2011.

RAVINDRAN, V.; COWIESON, A.J.; SELLE, P.H. Influence of dietary electrolyte balance and microbial phytase on growth performance, nutrient utilization, and 
excreta quality of broiler chickens. Poultry Science, Oxford, v. 87, p. 677-688, 2008.

RONDÓN, E.O.O.; MURAKAMI, A.E.; FURLAN, A.C.; GARCIA, J. Exigências nutricionais de sódio e cloro e estimativa do melhor balanço eletrolítico da ração para frangos de corte na fase pré-inicial (1-7 dias de idade). Revista Brasileira de Zootecnia, Viçosa, v. 29, n. 4, p. 1162-1166, 2000.

ROSTAGNO, H.S.; ALBINO, L.F.T.; HANNAS, J.L.; DONZELE, J.L.; SAKOMURA, N.K.; PERAZZO, F.G.; SARAIVA, A.; RODRIGUES, P.B.; OLIVEIRA, R.F.; BARRETO, S.L.T.; BRITO, C.O. Tabelas Brasileiras Para Aves e Suínos: Composição de Alimentos e Exigências Nutricionais. 4.ed. Viçosa: Departamento de Zootecnia UFV, 2017. 488p.

SILVA, A.V.F.; FLEMMING, J.S.; BORGES, S.B. Fontes de sódio e relação sódio:cloro para frangos de corte. Revista Brasileira de Ciência Avícola, Campinas, v. 2, p. 1806-9061, 2000.

SILVA, J.D.B.; FUENTES, M.F.F.; FREITAS, E.R.; ESPÍNDOLA, G.B.; SOUSA, F.M.; CRUZ, C.E.B. Níveis de sódio em rações de pintos de corte na fase inicial. Revista Ciência Agronômica, Ceará, v. 37, n. 1, p. 84-90, 2006.

SILVA, R.A.G.; MAIER, J.C.; ANCIUTI, M.A.; GENTILINI, F.P.; LOPES, D.C.N.; KRABBE, ÉL. Uso de diferentes fontes de sódio na dieta de frangos de corte de 22 a 42 dias de idade sobre o desempenho e umidade da cama. Ciência Animal Brasileira, Goiás, v. 10, p. 1029-1036, 2009.

SILVA, J.H.V.; PASCOAL, L.A.F. Função e disponibilidade dos minerais. In: SAKAMOURA, N.K.; SILVA, F.G.P.; FERNANDES, J.B.K.; HAUSCHILD, L. Nutrição de não ruminantes. Jaboticabal: Funep-Unesp; 2014. p. 127-142.

SUTTLE, N.F. Mineral nutrition of livestock. 4.ed. Cambridge: CAB international, 2010. 565p. 
VIEIRA, S.L.; PENS JR, A.M.; POPHAL, S. ALMEIDA, J.C. Sodium requirements for the first seven days in broiler chicks. The Journal of Applied Poultry Research, Oxford, v. 12, p. 362-370, 2003.

VILLANUEVA, A.P.; CARDINAL, K.M.; KRABBE, E.L.; PENS, J.A.M.; RIBEIRO, A.M.L. Influência da via de fornecimento do cloreto de sódio - água ou ração - em frangos de corte de um a sete dias de idade. Revista Brasileira de Saúde e Produção Animal, Bahia, v. 16, p. 865-873, 2015.

WATKINS, S.E.; FRITTS, C.A.; YAN, F.; WILSON, M.L.; WALDROUP, P.W. The interaction of sodium chloride levels in poultry drinking water and the diet of broiler chickens. The Journal of Applied Poultry Research, Oxford, v. 14, p. $55-59,2005$. 